\title{
Urgent Need for the Pre-IPO Review Mechanism of Chinese Companies Listing in the U.S.
}

\author{
Tingting Zhang \\ Email: oreal88@163.com
}

\begin{abstract}
In the past 20 years, it seems very common for many Chinese companies to apply for listing in the United States. Some of them are affected by objective factors and some of them have their own financing needs. However, according to the research, it is found that the actual situation of such Chinese enterprises listed in the United States is uneven, and there are many well-known enterprises that have been exposed to financial fraud or other scandals. Based on the analysis of the reasons and situation of Chinese companies going to the United States for listing, taking the tension which has risen between Washington and Beijing into consideration, the author puts forward the conclusion that China needs to establish a pre-examination mechanism for Chinese companies going to the United States for listing.
\end{abstract}

Keywords: Chinese companies, American stock market, venture, capital income

\section{Background and current situation of Chinese companies going public in the United States}

\subsection{Relevant background}

A statistical study of the number of IPO companies in the U.S. stock market from 1993-2012 shows that $13.6 \%$ of foreign companies are listed in the U.S. stock market, with Chinese companies accounting for 19.7\% of the total. In the past, China has not placed significant restrictions on domestic companies going public in the United States. The decision as to whether a Chinese company should go public in the U.S. capital markets is entirely a corporate decision rather than a national decision. According to the Wind database, 458 Chinese companies had gone public in the U.S. by the end of 2020, resulting in a "Chinese stock" landscape in the U.S. stock market, with a cumulative financing scale of trillions.

Listing in the U.S. once became a popular financing method for many Chinese companies for five main reasons. First, the U.S. capital market is closely connected with the global capital market and listing in the U.S. can expand the international popularity and influence of enterprises. Second, China's economy has developed rapidly after the reform and opening up, and many promising enterprises have emerged. The listing of high-quality Chinese enterprises in the U.S. is welcomed by global investors. Third, the U.S. stock market has strict legal regulations. If a company is found to be financially fraudulent or harmful to investors' interests, it will be severely punished by the U.S. regulatory system, such as mandatory delisting and class action lawsuits. ${ }^{[1]}$ Therefore, a successful listing in the U.S. is a strong proof of the company's high reputation. Fourth, there are many Chinese companies with foreign equity participation listed in the U.S., which makes capital conversion easier and facilitates the exit of foreign equity participation capital. Fifth, the issuance of new shares in China is not entirely market oriented. It is objectively controlled by government supply, and the financing needs of some emerging industries are more easily realized overseas. ${ }^{[2]}$

In order to obtain a comprehensive and systematic understanding of the current situation of Chinese IPOs in the U.S., the author retrieved the data of Chinese companies listed in the U.S. in recent years through Compustat and Wind databases, and the data of Chinese domestic IPOs through CSMAR database and conducted a comparative analysis of the relevant data.

Table 1. Data Distribution By Year

\begin{tabular}{cccc}
\hline Year & Chinese Companies Listed in the United States & Chinese Companies Listed in China & Ratio \\
\hline Before2004 & 43 & 1266 & 0.034 \\
2004 & 18 & 100 & 0.180 \\
2005 & 23 & 66 & 1.533 \\
2006 & 32 & 0.485 & 63
\end{tabular}




\begin{tabular}{lccc}
\hline Year & Chinese Companies Listed in the United States & Chinese Companies Listed in China & Ratio \\
\hline 2007 & 58 & 126 & 0.460 \\
2008 & 28 & 77 & 0.364 \\
2009 & 27 & 99 & 0.273 \\
2010 & 49 & 349 & 0.140 \\
2011 & 5 & 282 & 0.018 \\
2012 & 3 & 155 & 0.019 \\
2013 & 6 & 2 & 3.000 \\
2014 & 15 & 125 & 0.120 \\
2015 & 12 & 193 & 0.062 \\
2016 & 12 & 224 & 0.054 \\
2017 & 25 & 436 & 0.057 \\
2018 & 48 & 105 & 0.457 \\
2019 & 36 & 203 & 0.177 \\
2020 & 34 & 396 & 0.086 \\
Total & 458 & 4217 & 0.109 \\
\hline
\end{tabular}

Supplementary notes: The above data does not include the delisted enterprises.

Table 1 shows the number of Chinese companies listed in the U.S., the number of domestic IPOs and the corresponding data ratio in recent years. According to Table 1, it can be found that: probably influenced by the policy and economic environment, the number of domestic IPOs approved by companies in China has fluctuated over the past decade. When the number of companies cleared in China increases, the number of companies opting to list in the U.S. decreases. This phenomenon suggests that domestic policies significantly influence Chinese companies to go public in the U.S.

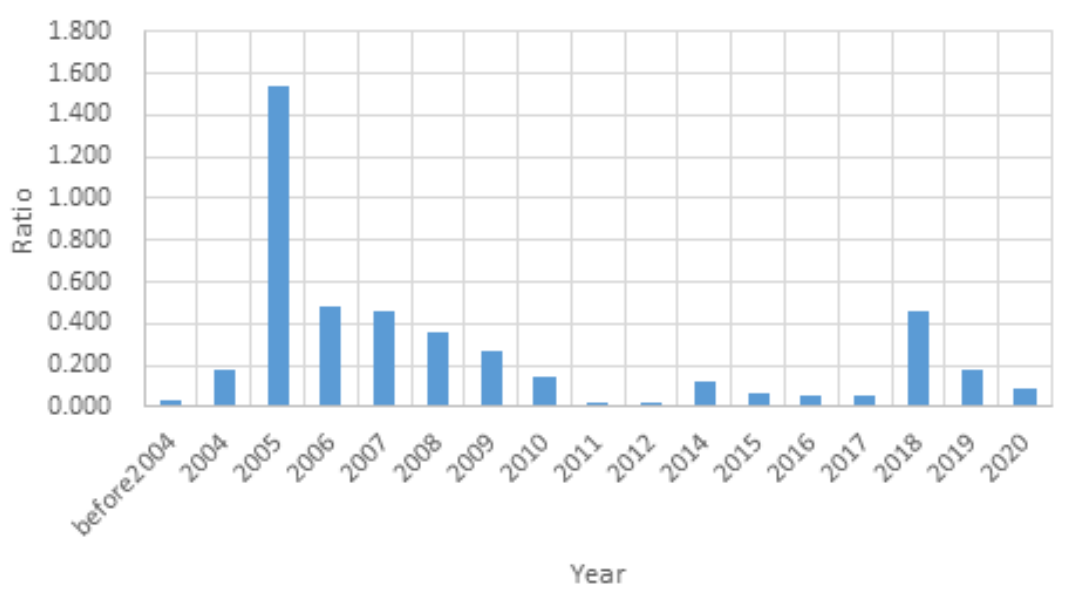

Figure 1. The ratio of the number of Chinese companies listed in the U.S. to the number of domestic listed companies (excluding 2013)

Figure 1 shows the distribution of the ratio of the number of Chinese companies listed in the U.S. to the number of domestic listed companies (excluding 2013). From Figure 1, it can be easily found that the ratio reached a peak around 2005, once entered a freezing point in 2011, and remained depressed until 2018 after a slight rebound. The impact of the credit crisis on Chinese stocks in 2010 may be the primary cause. Since June 2010, a number of Chinese stocks have been found to lack standardized financial processes, untimely information disclosure, and poor corporate governance. The scandal has severely damaged U.S. investors' evaluation of Chinese companies. In 2011, the financial fraud scandal of Longtop Group led to a round of "killing" of Chinese companies listed in the U.S., resulting in a crisis of confidence in Chinese companies. Fourteen Chinese companies went public in the U.S. in 2011, and 41 were delisted. ${ }^{[3]}$ The scandal of financial fraud and inflated business was exposed shortly after the listing of Luckin Coffee on NASDAQ in May 2019, causing widespread 
concern in the U.S. media. The adverse impact of the Luckin falsification incident went far beyond its share price plunge but sparked a storm of being brawled among China concept stocks. Short-selling agency Wolfpack Research has been working on several companies, including Chinese companies iQiyi and Genshuixue, in quick succession, causing a collective collapse in the Chinese stock section. Although it cannot be ruled out that some of the companies were maliciously speculated by shorting agencies, objectively, investors have already experienced a crisis of confidence in Chinese stocks. Even worse, the crisis may also affect the trust in the group of Chinese companies preparing to go public in the U.S.

To further verify this reason, the author focused on comparing and analyzing the number of companies listed and delisted in the U.S. five years before and after the credit crisis of Chinese stocks in 2010 and created Table 2.

Table 2. List of companies listed and delisted in the U.S. in the five years before and after the credibility crisis of Chinese stocks in 2010

\begin{tabular}{ccccc}
\hline Number Compare & $2006-2010$ & $2011-2015$ & Increase or decrease & Up or down (\%) \\
\hline Number of Listings & 194 & 41 & -153 & $-78.9 \%$ \\
Number of Delistings & 6 & 122 & +116 & $+1933 \%$ \\
\hline
\end{tabular}

As can be seen from Table 2, the number of Chinese companies successfully listed in the U.S. in the five years following the Chinese stock credibility crisis declined significantly, while the number of delistings reached nearly 20 times the precrisis level.

In summary, two conclusions can be drawn. First, the decline in the credibility of Chinese stocks affects the applications of other Chinese companies to list and raise capital in the United States. When Chinese companies are exposed to scandals on the U.S. stock market, the number of Chinese companies that can subsequently succeed in their U.S. IPOs declines significantly, while the number of delisted companies increases significantly. Second, the leniency or strictness of China's domestic securities regulator affects whether companies decide to list in the United States. When it becomes more difficult for Chinese companies to list domestically, for example, from 2005 to 2008 and in 2013, the percentage of Chinese companies going public in the U.S. increases significantly.

\subsection{Problems}

\subsubsection{Regulatory loopholes have caused a credibility crisis for Chinese stocks}

Most Chinese companies use VIE agreement control structure, the management of these Chinese companies does not control the operating company according to the proportion of equity, but by entering into various complex agreements for actual control. The actual controller hides behind multiple agreements, and the financial behavior is often difficult to be genuinely open and transparent. A significant portion of domestic enterprises has irregular financial processes, untimely information disclosure, and imperfect corporate governance, which makes it difficult for the real operation circumstances of U.S.-listed enterprises to be audited and monitored by the SEC without domestic pre-approval. Regarding the companies, although the VIE structure can effectively circumvent U.S. government controls and disputes, investing in Chinese stocks becomes more like a gamble against the background of the lack of audits by regulators, which can lead to a major loss of trust in Chinese companies in the market. Shorting agencies are also preying on them like vultures hunting for food. Once a Chinese company goes into meltdown, it will trigger a chain reaction that will tarnish the image of Chinese companies.

\subsubsection{The listing of enterprises in specific fields in the U.S. poses potential risks to national security}

The evolution of the third technological revolution, artificial intelligence, big data applications, and other rapid development gives rise to the emergence of science and technology innovation enterprises in specific fields, especially in commercially mature big data applications. The big data industry has become the frontier field of global high-tech industry competition, and the developed countries represented by the U.S., Japan, and Europe have launched a new round of information strategy with big data as the core. The previous inter-company competition has been transformed into a competition for information and data. Didi, which was only listed on the U.S. New York Stock Exchange on July 1 this year, was exposed the next day for allegedly leaking important data, followed by the removal of 25 of its apps. It has already fallen below its offering price in ten days of listing, with investors in mourning. Meanwhile, China is aware of the major security risks associated with listing these companies in the U.S.

\section{Analysis of the necessity of setting up a pre-approval system}

The author believes that approval of Chinese companies proposing to go public in the U.S. can identify and correct problems from the front end. Setting up an approval system demonstrates that China respects the right of domestic companies to raise capital overseas, while filtering out potential risks that could harm the interests of the country and other Chinese 
companies. It is regarded as a responsible attitude both internally and externally.

\subsection{Reduce the credibility risk of Chinese stocks}

Li Youxing, a professor at Zhejiang University Guanghua Law School, believes that "through the VIE structure, the profits of the domestic entity transfer to the overseas company, and then listed overseas. In addition, there is no reporting of the overall operation to the domestic regulation departments before and after the Chinese concept stocks go public." The probability of a crisis is also higher for the securities regulators in both countries, due to the regulatory gaps in those companies. Once a problematic company goes public in the U.S., the interests of global investors will be damaged. Chinese companies may experience a public scourge, which will be detrimental to other Chinese companies that need to raise capital in the U.S. and will damage China's international image. Therefore, by setting up a pre-approval process for overseas listings, China can effectively screen out companies at the front end that intend to cover up undesirable issues by setting up complex shareholding structures. For companies eager to go public in the U.S., it is beneficial for them to improve their standards. Companies are bound to operate more attentively and strive for perfection in all aspects of business management, finance, and information security to make their companies withstand the test to meet the dual strict requirements of both the Chinese review authorities and the SEC.

\subsection{Reducing dual security risks}

First, it reduces the risk of capital annexation by enterprises due to unfamiliarity with the rules. After listing in the U.S., Chinese companies may not be able to adapt to the rules of the U.S. securities market in a completely unfamiliar cultural environment and capital market environment. Changes in share price and equity structure may lose control and cause unnecessary disasters for the companies.

Second, it reduces the risk of information security. The listing of Chinese companies in the U.S. is subject to review by multiple U.S. departments, and the shareholding structure may also change with changes in secondary market transactions after the listing. For domestic Internet giant companies that hold important data, there is a risk of leakage of important information during this process. On July 10, the Cyberspace Administration of China released draft measures for network security review, stipulating that operators holding personal information of more than 1 million users must declare network security review when they go public abroad. ${ }^{[4]}$ This is an important step forward in regulatory policymaking. Therefore, China should establish a sound pre-approval system as soon as possible to maintain national information security. The "renegade" companies that may leak important information must be detected to eliminate the problem in the bud so that cases like Didi will not occur again.

\subsection{Avoiding the risk of political involvement}

As the fuse of financial fraud at Luckin Coffee has given some U.S. politicians additional fodder for political grandstanding, the U.S. Senate voted in May 2020 to pass the Holding Foreign Companies Accountable Act, purporting to apply to all foreign companies seeking to list in the United States. However, Republican Senator John Kennedy and Democratic Senator Van Hollen have made it clear that they are primarily targeting Chinese companies. Kennedy has even hinted that it is a response to "China's slide to the top," and Hollen has made no secret of its political nature, saying it stems from "political concerns arising from increased tensions between the U.S. and China."[3]

Therefore, based on the principle that a problem can be solved with proper self-management, the auditing mechanism will reduce the occurrence of problems, establish a good reputation and image of Chinese enterprises, and help the country reduce the exposure to the risk of becoming a political target.

\section{How to establish a review mechanism and its essential functions}

\subsection{Establishment of a specialized review body}

For Chinese companies that demand to go public abroad, the government should establish a special review entity to receive applications. This entity should have a well-developed operating system and process and establish a panel of experts from the national securities commission, information security, economics, and management fields to review and supervise the submitted companies in various aspects. The applicant must be investigated and reviewed by the expert group to verify and approve before proceeding to the next step of submitting a listing application abroad. The agency has the right to pursue companies that have caused serious consequences by concealing the real circumstances.

\subsection{Deep penetration, filling the regulatory gap of SEC}

The Chinese government establishes a pre-approval mechanism that can effectively bridge the regulatory gap brought 
about by the issue of the company's complementary VIE structure. A team of experts will conduct a deep penetration of the company, investigate and review the company, and issue an evaluation report containing the shareholding structure, management and financial aspects, which will provide a reference value for its subsequent financing in the U.S. market. If the Chinese government finds serious problems with the company during the review process, it will terminate or delay the company's plan to go public in the U.S. and rule out the junk companies for investors. This ensures that the company's real situation meets the basic requirements of an SEC IPO and provides more comprehensive protection for global investors.

\subsection{Assistance in the enterprise transitions}

Since Chinese companies are rooted in the Chinese social and investment environment and lack practical experience in the U.S. investment environment, pre-approval should play a role in helping companies get familiar with and adapt to the new environment in advance. It should help eligible Chinese companies understand the rules of the U.S. market so that Chinese companies can make a smooth transition and better adapt to the local investment rules and capital environment after listing in the U.S.

\section{Summary}

In the current complex international financial environment, especially with the increasing friction between China and the U.S., the influence of the capital market on the real sector cannot be underestimated. Listing in the U.S. brings financing to Chinese companies and poses many threats. The consequences of some of these problems have already been highlighted, while others are still in the process of fermentation, and it is not yet known whether they will cause incalculable damage. There is no doubt that a pre-censorship mechanism for U.S. listings in China is imminent and would be beneficial for company construction, China's image, information security, and create value for global investors.

\section{References}

[1] Fuerst O. A theoretical analysis of the investor protection regulations argument for global listing of stocks[J]. Yale University Working Paper. 1998.

[2] Li Xuan, Guo Ying, Xu Hao. Why do Chinese Firms Choose to List in U.S.and the Trend Change. Economic Research Guide. 2019; (22): 95-104,106.

[3] Jiang Shan, Wang Chen. The Way to Solve the Confidence Crisis of China Concept Stocks. China Business Times. No. 003, 2020.04.09.

[4] Xu Lifan. Chinese companies being restricted from listing in the United States may not be all bad things. China Business Times. No. 003, 2020.12.01. 